\title{
Associations between the number of natural teeth and the maternal age at childbirth or history of parity in postmenopausal women: The 2010-2012 Korea national health and nutrition examination survey
}

\author{
Kyungdo Han ${ }^{1, A-F}$, InSoo Kim 2, B-F, Yong-Gyu Park, A-F, Jun-Beom Park ${ }^{3, A-F}$ \\ 1 Department of Biostatistics, College of Medicine, The Catholic University of Korea, Seoul, Republic of Korea \\ 2 Department of Oral and Maxillofacial Surgery, College of Medicine, The Catholic University of Korea, Seoul, Republic of Korea \\ ${ }^{3}$ Department of Periodontics, College of Medicine, The Catholic University of Korea, Seoul, Republic of Korea \\ A - research concept and design; $\mathrm{B}$ - collection and/or assembly of data; $\mathrm{C}$ - data analysis and interpretation; \\ $D$ - writing the article; $E$ - critical revision of the article; $F$ - final approval of article
}

Address for correspondence

Jun-Beom Park

E-mail: jbassoonis@yahoo.co.kr

\section{Funding sources}

This research was supported by the Basic Science Research Program through the National Research Foundation of Korea (NRF), funded by the Ministry of Science, ICT \& Future Planning (NRF-2017R1A1A1A05001307).

Conflict of interest

None declared

\section{Acknowledgements}

This authors are grateful for the support received from the Basic Science Research Program through the National Research Foundation of Korea (NRF) funded by the Ministry of Science, Information and Communication Technology \& Future Planning (NRF2017R1A1A1A05001307), and would also like to thank the Korea Centers for Disease Control and Prevention for providing the data.

Received on November 9, 2015 Revised on November 29, 2015 Accepted on April 25, 2016

\begin{abstract}
Background. The relationship between reproductive factors, including pregnancy and delivery, and the number of teeth in postmenopausal women remains to be revealed.
\end{abstract}

Objectives. The aim of this study was to evaluate the relationship between age at first and last delivery, parity and the number of natural teeth in postmenopausal women, using nationally representative data.

Material and methods. Data from the Korea National Health and Nutrition Examination Survey between 2010 and 2012 were used, and the analysis in this study was confined to a total of 4,060 respondents who had gone through menopause and had no missing values for the reproductive factors and outcome variables. The total number of natural teeth was then calculated after excluding third molars, and frequency of tooth brushing was recorded as oral health behavior. Univariate and multivariate logistic regression analyses were used to assess the associations between the number of natural teeth and reproductive factors.

Results. Both a woman's age at her last childbirth and the number of pregnancies had statistically significant effects on the number of natural teeth remaining after menopause. With each one-year increase of age at a woman's last delivery, the number of natural teeth decreased by a value of $0.12(p<0.05)$. Similar trends were seen with increases in parity, which resulted in decreases in the number of natural teeth by 0.65 $(p<0.05)$. The odds ratios of the percentage of individuals with a 20 or fewer teeth tended to increase with increases in the woman's age at her last childbirth.

Conclusions. This study identified an association between the number of natural teeth and a woman's age at her last childbirth as well as between the number of natural teeth and parity. Higher ages at last childbirth and higher parity were found to be potential risk indicators for tooth loss in postmenopausal women.

Key words: epidemiology, hormone replacement therapy, menopause, parity, tooth loss

DOI

$10.17219 /$ acem $/ 62832$

Copyright

Copyright by Author(s)

This is an article distributed under the terms of the

Creative Commons Attribution Non-Commercial License

(http://creativecommons.org/licenses/by-nc-nd/4.0/) 
Menopause is the event marking the cessation of ovarian activity sufficient to support monthly menstrual cycles. ${ }^{1}$ Menopause is reported to occur at approximately 50 years of age, usually between 45 and 54 years in a healthy, wellnourished population worldwide. ${ }^{2,3}$ The median age at menopause is earlier for women with an earlier age at their first childbirth, women with a late age at menarche and women who have had no children; menopause tends to occur at later ages among women with higher parity. ${ }^{2,4-6}$ Smoking and poor socioeconomic status are also associated with earlier menopause. ${ }^{3}$ The suggestion that race/ ethnicity may be a significant independent predictor of the timing of natural menopause has also been reported. ${ }^{5}$

Previous studies have shown that the incidence of delivery during adolescence or at an advanced age was significantly higher in subjects with osteoporosis than in those without osteoporosis. $^{7,8}$ It was suggested that pregnancies during adolescence and pregnancies at an advanced maternal age may result in unfavorable birth outcomes as well as maternal complications, including adverse bone health effects. ${ }^{7}$

However, the relationship between reproductive factors, including the history of pregnancy and delivery, and the number of teeth in postmenopausal women is unclear. This study therefore evaluated the relationship between age at first and last deliveries, parity and the number of natural teeth in postmenopausal women using nationally representative data.

\section{Material and methods}

\section{Overview of the survey and participants}

The data used in this study were derived from the Korea National Health and Nutrition Examination Survey (KNHANES), which was conducted between 2010 and 2012 by the Division of Chronic Disease Surveillance under the Korea Centers for Disease Control and Prevention and the Korean Ministry of Health and Welfare. ${ }^{9}$ The KNHANES is a nationwide survey of non-institutionalized civilians that uses a stratified and multi-stage probability sampling design with a rolling survey sampling model. The sampling units were based on the population and housing census from the National Census Registry in Korea, which includes age, gender and geographic area. To represent the Korean population with sample participants, all the statistics in the survey were calculated using sample weights that consider survey non-response, the complex survey design and post-stratification.

\section{Menopause and hormone replacement therapy}

Initially, a total of 14,396 women over 19 years old participated in the KNHANES survey. The analysis in this study was confined to a total of 4,060 respondents who had gone through menopause (aged 46 to 75 years) and had no missing values for reproductive factors and outcome variables. Data regarding reproductive factors were collected by asking the participants to recall their age at their first and last deliveries, their age at menopause, and their gravidity and parity. All the participants in the survey signed informed consent forms prior to participation. The survey was reviewed and approved by the Institutional Review Board of the Korea Centers for Disease Control and Prevention.

\section{Sociodemographic and lifestyle variables}

All the participants were asked about sociodemographic and lifestyle variables by trained interviewers. Education level was categorized into 2 groups using the criteria of middle school graduate or less. Monthly household income was divided into quartiles after adjusting for the number of family members. The lowest quartile included households with a monthly income $<1092.40$ USD. Participants were categorized into 2 groups depending on the amount of alcohol consumed per day for a month before the interview, using the criteria of $\geq 30$ g/day or less. ${ }^{10}$ Smoking status was categorized into 2 groups - those who had never smoked and those who had - according to the respondents' answers on the self-reporting questionnaire. Based on responses to a modified form of the International Physical Activity Questionnaire for Koreans, individuals were regarded as regular physical exercisers if they performed moderate exercise more than 5 times per week for over $30 \mathrm{~min}$ per session or performed vigorous exercise more than 3 times per week for over $20 \mathrm{~min}$ per session. ${ }^{11}$

\section{Measurements and definition of obesity}

Anthropometric measurements were performed by a trained staff member. Body weight and height were measured to the nearest $0.1 \mathrm{~kg}$ and $0.1 \mathrm{~cm}$, respectively, with the participants in light indoor clothing without shoes. Body mass index was calculated as body weight (kg) divided by the squared height $\left(\mathrm{m}^{2}\right)$. Waist circumference was measured at the narrowest point between the lower edge of the rib cage and the iliac crest with the participant in a standing position. ${ }^{12,13}$

\section{Biochemical measurements}

The physical measurements of the participants were done by trained staff members in the Division of Chronic Disease Surveillance under the Korea Centers for Disease Control and Prevention and the Korean Ministry of Health and Welfare.

A standard mercury sphygmomanometer (Baumanometer; W.A. Baum Co., Inc., Copiague, NY, USA) was used for blood pressure measurement. Systolic blood pres- 
sure and diastolic blood pressure were measured twice at 5-min intervals, and the average values were used for the analysis.

To measure concentrations of serum fasting plasma glucose, total cholesterol, triglycerides and high-density lipoprotein-cholesterol, a blood sample was collected from the antecubital vein of each participant after fasting for $>8 \mathrm{~h}$. Blood samples were analyzed within $24 \mathrm{~h}$ of transportation. Levels of serum fasting plasma glucose, total cholesterol, triglycerides and high-density lipoprotein-cholesterol were measured with a Hitachi Automatic Analyzer 7600 (Hitachi, Tokyo, Japan) by enzymatic methods using commercially available kits (Daiichi, Tokyo, Japan). ${ }^{14}$

\section{Description of metabolic syndrome, diabetes and hypertension}

Metabolic syndrome was defined according to the American Heart Association/National Heart, Lung, and Blood Institute Scientific Statement criteria for Asians. ${ }^{15}$ According to these criteria, three or more of the following criteria must be fulfilled to be diagnosed with metabolic syndrome: waist circumference $\geq 90 \mathrm{~cm}$ in men and $\geq 80 \mathrm{~cm}$ in women; fasting triglycerides $\geq 150 \mathrm{mg} / \mathrm{dL}$ or use of lipid-lowering medication; high-density lipoproteincholesterol $<40 \mathrm{mg} / \mathrm{dL}$ in men and $<50 \mathrm{mg} / \mathrm{dL}$ in women or use of medication; blood pressure $\geq 130 / 85 \mathrm{~mm} \mathrm{Hg}$ or use of antihypertensive medication; and fasting blood glucose $\geq 100 \mathrm{mg} / \mathrm{dL}$ or current use of anti-diabetes medication. Diabetes was diagnosed when fasting blood sugar was $>126 \mathrm{mg} / \mathrm{dL}$ or when the individual was currently using anti-diabetic medications. ${ }^{16}$ Hypertension was defined as a systolic blood pressure of $>160 \mathrm{~mm} \mathrm{Hg}$ or a diastolic blood pressure of $>90 \mathrm{~mm} \mathrm{Hg}$ or the current use of systemic antihypertensive drugs. ${ }^{17}$

\section{Oral health behavior and number of natural teeth}

In the KNHANES, the time of day when tooth brushing was done (before or after breakfast, lunch and dinner and before bedtime) was recorded as oral health behavior. The current study used this data to calculate the total number of times the teeth were brushed per day as the frequency of daily tooth brushing.

The oral health data included variables that recorded the status for each of the 32 teeth as one of the four categories: primary tooth present, permanent tooth present, tooth not present or permanent dental root fragment present. In the present study, a natural tooth was considered present if the status was one of the first 2 categories, and absent if the status was one of the last 2 categories; the total number of natural teeth was then calculated after excluding third molars. Based on this information, the participants were classified into one of two groups: $\geq 21$ or $\leq 20$. An isomeric tooth pair was defined as present if the same types of teeth (for example the right central incisor, right lateral incisor, right canine, right first premolar, etc.) were present on both the maxilla and the mandible, and 14 pairs were considered the maximum number. As part of the KNHANES quality control, training was provided to each examiner to minimize errors in the measurement of the number of teeth remaining.

\section{Statistical analyses}

All data are presented as means \pm standard error or as percentages (standard error). If necessary, logarithmic transformation was performed to achieve a normal distribution. Student's t-test or a one-way analysis of variance was used to investigate differences in the presence of periodontal treatment needs according to the variables. Univariate and multivariate logistic regression analyses were used to assess associations between the number of natural teeth and hormone replacement therapy. The adjusted odds ratio and $95 \%$ confidence interval of the individuals with 20 or fewer natural teeth were calculated using a multivariate logistic regression model. Model 1 was unadjusted. Model 2 was adjusted for age, smoking, drinking, exercise, education and income. Model 3 was adjusted for age, smoking, drinking, exercise, education, income, body mass index, metabolic syndrome and hormone replacement therapy. Statistical analyses were performed using the survey procedure of a statistical software package (SAS v. 9.2 for Windows, SAS Institute, Cary, NC, USA) to account for the complex sampling design. Two-sided p-values of $<0.05$ were considered statistically significant.

\section{Results}

Table 1 describes the baseline characteristics of the study participants according to the number of natural teeth remaining. The mean age, waist circumference, metabolic syndrome and income were significantly lower in participants with 21 or more natural teeth. The frequency of tooth brushing per day and frequency of dental checks within a year were significantly higher in participants with 21 or more natural teeth. Trends in age at first and last delivery and parity showed significant differences between the individuals with 20 teeth or fewer and those with more than 21 teeth.

The percentages of individuals with given numbers of teeth categorized by reproductive factors is shown in Fig. 1. The percentage of individuals with 28 teeth or 21-27 teeth increased with increases in age at the first delivery. However, individuals with 28 teeth or 21-27 teeth decreased with increases in age at the last delivery. The percentage of individuals with 28 teeth or 21-27 teeth seemed to decrease with increases in parity. 
Fig. 1. The percentage of individuals according to the number of teeth: a) the percentage of individuals according to the number of teeth, categorized by their age at their first delivery; b) the percentage of individuals according to the number of teeth, categorized by their age at their last delivery; b) the percentage of individuals according to the number of teeth, categorized by parity

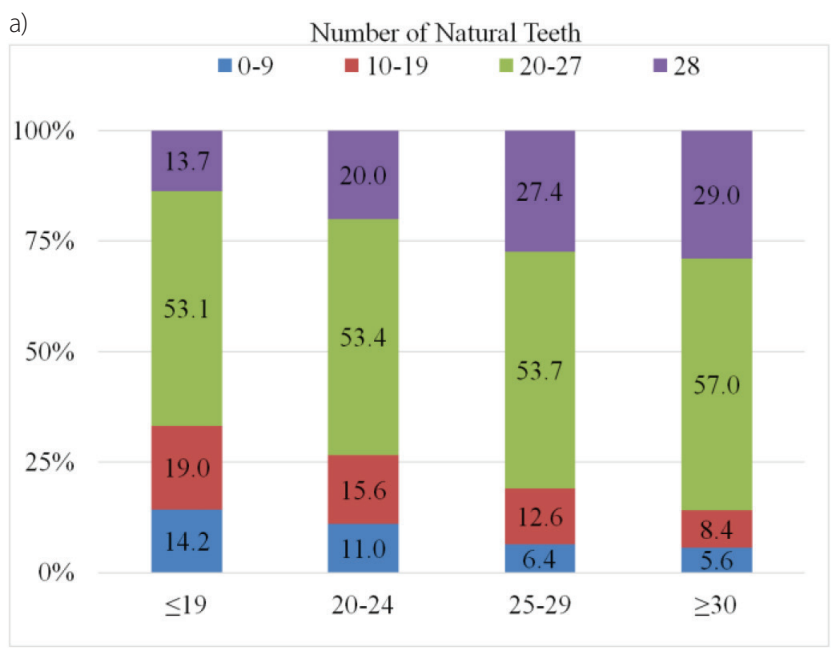

Age at first delivery

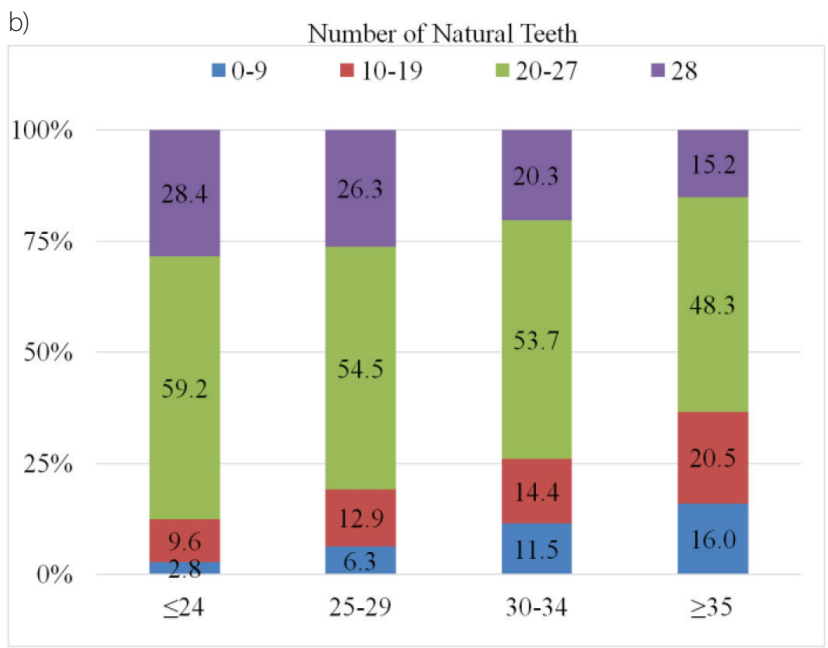

Age at last delivery

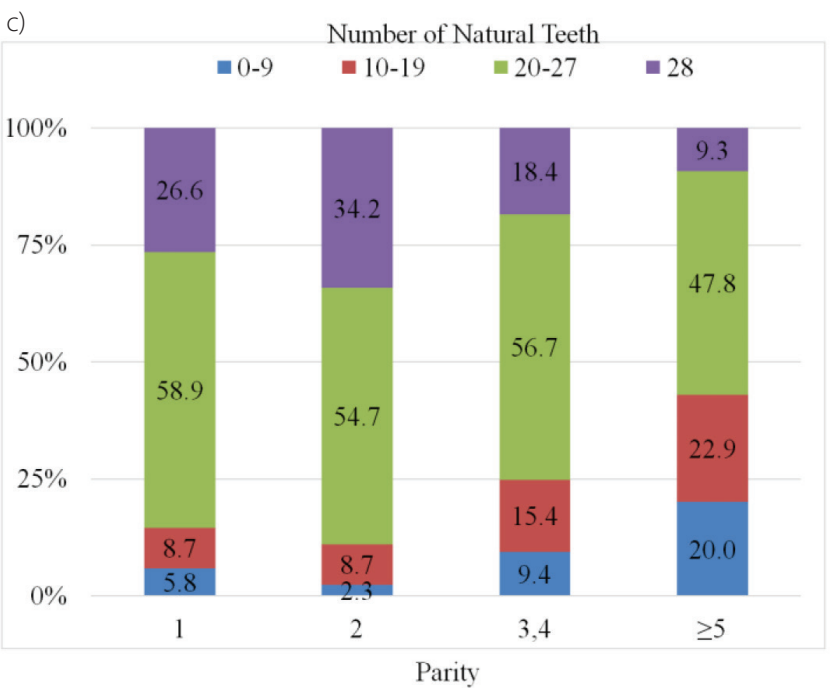

Table 1. Baseline characteristics of the study group according to the number of natural teeth

\begin{tabular}{|c|c|c|c|c|}
\hline \multirow{2}{*}{\multicolumn{2}{|c|}{ Variables }} & \multicolumn{3}{|c|}{ The number of natural teeth } \\
\hline & & $\leq 20$ & $\geq 21$ & $\mathrm{p}$-value* \\
\hline \multicolumn{2}{|c|}{ Unweighted (n) } & 1.159 & 2.901 & \\
\hline \multicolumn{2}{|l|}{ Age (years) } & $64.8 \pm 0.3$ & $58.3 \pm 0.2$ & $<0.0001$ \\
\hline \multicolumn{2}{|c|}{$\begin{array}{l}\text { Body mass index } \\
\left(\mathrm{kg} / \mathrm{m}^{2}\right)\end{array}$} & $24.6 \pm 0.1$ & $24.4 \pm 0.1$ & 0.1881 \\
\hline \multicolumn{2}{|c|}{$\begin{array}{l}\text { Waist circumference } \\
(\mathrm{cm})\end{array}$} & $84.1 \pm 0.4$ & $81.9 \pm 0.2$ & $<0.0001$ \\
\hline \multicolumn{2}{|c|}{ Metabolic syndrome } & $57.8(2.0)$ & $44.8(1.2)$ & $<0.0001$ \\
\hline \multicolumn{2}{|c|}{$\begin{array}{l}\text { Alcohol drinking } \\
\text { (> } 15 \mathrm{~g} / \text { day) }\end{array}$} & $0.1(0.1)$ & $1.0(0.3)$ & 0.0018 \\
\hline \multicolumn{2}{|c|}{ Smoking (ever) } & $6.6(1.1)$ & $5.3(0.6)$ & 0.2469 \\
\hline \multicolumn{2}{|l|}{ Stress (yes) } & $27.9(1.5)$ & $25.9(1.0)$ & 0.2964 \\
\hline \multicolumn{2}{|c|}{ Spouse (yes) } & $68.6(1.7)$ & 79.9 (1) & $<0.0001$ \\
\hline \multicolumn{2}{|c|}{ Occupation (yes) } & $47.3(2)$ & 49.7 (1.2) & 0.2573 \\
\hline \multicolumn{2}{|c|}{ Exercise (yes) } & $15.7(1.5)$ & $17.3(1)$ & 0.3243 \\
\hline \multicolumn{2}{|c|}{$\begin{array}{l}\text { Frequency of tooth } \\
\text { brushing per day }\end{array}$} & $2.15 \pm 0.03$ & $2.25 \pm 0.02$ & 0.0023 \\
\hline \multicolumn{2}{|c|}{$\begin{array}{l}\text { Dental checkup } \\
\text { within a year (yes) }\end{array}$} & 15.6 (1.3) & $21.9(1)$ & $<0.0001$ \\
\hline \multicolumn{2}{|c|}{$\begin{array}{l}\text { Income (the lowest } \\
\text { quartile) }\end{array}$} & $43.7(1.7)$ & 20.9 (1) & $<0.0001$ \\
\hline \multicolumn{2}{|c|}{$\begin{array}{l}\text { Education (middle- } \\
\text { school graduate or } \\
\text { lower) }\end{array}$} & $10.6(1.3)$ & 33.1 (1.2) & $<0.0001$ \\
\hline \multirow{4}{*}{$\begin{array}{l}\text { Age } \\
\text { at first } \\
\text { childbirth }\end{array}$} & -19 & $8.2(1)$ & $5.2(0.5)$ & \multirow{4}{*}{$<0.0001$} \\
\hline & $20-24$ & $58.6(1.9)$ & $48.7(1.2)$ & \\
\hline & $25-29$ & $29.3(1.8)$ & $39.3(1.2)$ & \\
\hline & $30-$ & $3.9(0.8)$ & $6.7(0.6)$ & \\
\hline \multirow{4}{*}{$\begin{array}{l}\text { Age } \\
\text { at last } \\
\text { childbirth }\end{array}$} & -24 & $5.2(0.9)$ & $9.9(0.8)$ & \multirow{4}{*}{$<0.0001$} \\
\hline & $25-29$ & $35.4(1.8)$ & $46.4(1.1)$ & \\
\hline & $30-34$ & $37.5(1.7)$ & $31.6(1.1)$ & \\
\hline & $35-$ & $21.9(1.5)$ & $12.1(0.8)$ & \\
\hline \multirow{3}{*}{ Parity } & 1.2 & $23.8(1.7)$ & $54.9(1.3)$ & \multirow{3}{*}{$<0.0001$} \\
\hline & 3.4 & $52.6(1.8)$ & $36.8(1.2)$ & \\
\hline & $\geq 5$ & $23.6(1.6)$ & $8.3(0.6)$ & \\
\hline
\end{tabular}

Data are presented as means \pm standard error (SE) or percentages (SE); ${ }^{*} p$-values were obtained by independent t-test for continuous variables or chi-square test for categorical variables. 
Table 2 shows the multivariate regression analysis of age at first and last deliveries, parity and the number of natural teeth after adjustments. A woman's age at her last delivery and the number of pregnancies had statistically significant effects on the number of natural teeth. With each increase of one year in a woman's age at her last delivery, the number

Table 2. Multivariate regression analysis of participants' age at first/last delivery, parity and number of natural teeth

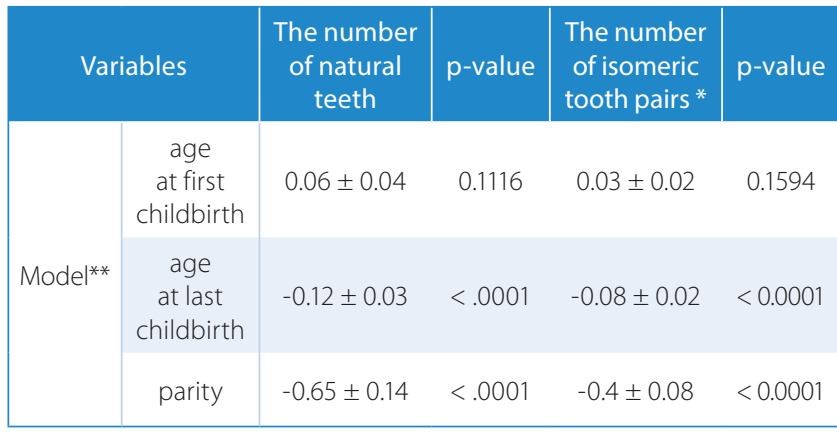

*An isomeric tooth pair was defined as present if the same types of teeth (forexample; right central incisor, right lateral incisor, right canine, etc.) were present on both the maxilla and the mandible, and the maximum number was 14 pairs; **Model: age, smoking, drinking exercise, education, income, body mass index, metabolic syndrome and hormone replacement therapy adjusted. of natural teeth decreased by a value of $0.12(\mathrm{p}<0.05)$. Similar trends were seen with increases in parity, which resulted in decreases in the number of natural teeth to 0.65 ( $p<0.05)$. Similar trends were seen with an increase in parity, which resulted in a decrease of the number of natural teeth by 0.65 $(\mathrm{p}<0.05)$. A woman's age at her first delivery did not have significant effects on the number of natural teeth.

Table 3 shows the adjusted odds ratios and 95\% confidence intervals from the multivariate logistic regression analyses for individuals with 20 or fewer natural teeth in relation to age at first childbirth, age at last childbirth and parity. According to the trend analysis, the odds ratios of the percentage of individuals with $\leq 20$ teeth tended to increase with increases in age at last childbirth. The adjusted odds ratios and 95\% confidence intervals of the individuals with $\leq 20$ teeth were 1.094 (1.073, 1.115), 1.042 (1.017, $1.068)$ and $1.034(1.008,1.06)$ for Model 1 , Model 2 and Model 3, respectively. The odds ratios of the percentage of individuals with 20 or fewer teeth tended to increase with increases in parity. The adjusted odds ratios and 95\% confidence intervals of the individuals with $\leq 20$ teeth were 1.634 (1.517, 1.76), 1.158 (1.07, 1.253) and 1.136 (1.044, 1.236) for Model 1, Model 2 and Model 3, respectively.

Table 3. Adjusted odds ratio and 95\% confidence interval of individuals with $\leq 20$ natural teeth in the multivariate logistic regression model

\begin{tabular}{|c|c|c|c|c|c|c|}
\hline Variables & $\begin{array}{l}\text { Odd ratios (95\% } \\
\text { confidence of } \\
\text { interval) }\end{array}$ & $p$-value & $\begin{array}{c}\text { Odd ratios ( } 95 \% \\
\text { confidence of interval) }\end{array}$ & $p$-value & $\begin{array}{l}\text { Odd ratios }(95 \% \\
\text { confidence of } \\
\text { interval) }\end{array}$ & $p$-value \\
\hline $\begin{array}{l}\text { Age at first } \\
\text { childbirth* }\end{array}$ & $0.985(0.953,1.019)$ & 0.3824 & & & & \\
\hline $\begin{array}{l}\text { Age at last } \\
\text { childbirth* }\end{array}$ & & & $1.034(1.008,1.06)$ & 0.0102 & & \\
\hline \multirow[t]{2}{*}{ Parity* } & & & & & $1.136(1.044,1.236)$ & 0.0031 \\
\hline & \multicolumn{2}{|c|}{ model 1} & \multicolumn{2}{|c|}{ model 2} & \multicolumn{2}{|c|}{ model 3} \\
\hline Age & $1.118(1.100,1.136)$ & $<0.0001$ & $1.111(1.092,1.13)$ & $<0.0001$ & $1.106(1.086,1.126)$ & $<0.0001$ \\
\hline Smoking & $1.833(1.059,3.173)$ & 0.0303 & $1.872(1.089,3.216)$ & 0.0232 & $1.882(1.086,3.261)$ & 0.0242 \\
\hline Drinking & $0.934(0.734,1.188)$ & 0.5774 & $0.944(0.741,1.203)$ & 0.6406 & $0.942(0.739,1.201)$ & 0.6292 \\
\hline Exercise & $1.141(0.876,1.485)$ & 0.3269 & $1.161(0.895,1.506)$ & 0.2619 & $1.132(0.871,1.47)$ & 0.3539 \\
\hline $\begin{array}{l}\text { Education (high- } \\
\text { school graduate } \\
\text { or higher) }\end{array}$ & $0.468(0.342,0.64)$ & $<0.0001$ & $0.442(0.323,0.605)$ & $<0.0001$ & $0.485(0.353,0.665)$ & $<0.0001$ \\
\hline $\begin{array}{l}\text { Income (the } \\
\text { lowest quartile) }\end{array}$ & $1.206(0.979,1.486)$ & 0.0778 & $1.238(1.007,1.523)$ & 0.043 & $1.202(0.976,1.48)$ & 0.0833 \\
\hline Body mass index & $0.981(0.947,1.017)$ & 0.3015 & $0.982(0.949,1.018)$ & 0.3223 & $0.979(0.945,1.015)$ & 0.2469 \\
\hline $\begin{array}{l}\text { Metabolic } \\
\text { syndrome }\end{array}$ & $1.130(0.903,1.414)$ & 0.2866 & $1.144(0.913,1.434)$ & 0.2434 & $1.128(0.901,1.413)$ & 0.2944 \\
\hline $\begin{array}{l}\text { Hormone } \\
\text { replacement } \\
\text { therapy }\end{array}$ & $0.557(0.416,0.748)$ & $<0.0001$ & $0.574(0.428,0.770)$ & 0.0002 & $0.575(0.428,0.772)$ & 0.0002 \\
\hline
\end{tabular}

*Model 1: no adjustment; model 2: age, smoking, drinking exercise, education, income adjusted; model 3: age, smoking, drinking exercise, education, income, body mass index, metabolic syndrome and hormone replacement therapy adjusted. 


\section{Discussion}

This study aimed to identify the relationship between the number of natural teeth in postmenopausal Korean women and their reproductive history, specifically their age at their first childbirth, age at last childbirth and the number of pregnancies. The analysis revealed that an increased risk of tooth loss was associated with a history of delivery at an advanced maternal age, but it was not associated with a woman's age at her first delivery. Similarly, increased parity was associated with an increased risk of tooth loss.

An earlier report showed that higher-parity Japanese women are more likely to lose teeth, especially posterior isomeric pairs. ${ }^{18}$ Similarly, the number of teeth negatively correlated with the number of children among white and black non-Hispanic American women and among Danish women. ${ }^{19,20}$ However, another report found no evidence supporting the hypothesis that the more children a woman has the more teeth she loses. ${ }^{21}$ This nationwide, population-based and representative sample of Koreans clearly revealed that higher parity and a history of delivery at an advanced maternal age were associated with a loss of teeth.

The mechanism underlying the association between the number of teeth and a woman's age at her last childbirth and parity has not been fully revealed yet. There is a saying that a mother loses one tooth every time she gives birth to a child. ${ }^{18,20}$ Pregnancy and parturition are known to have a tremendous effect on maternal health. ${ }^{18}$ Some consider that pregnancy and lactation, with the associated calcium depletion, could aggravate the development of caries. ${ }^{22}$ During pregnancy, certain salivary cariogenic microorganisms may increase in number, while salivary pH decreases..$^{23}$ Moreover, pregnancy entails physiological adaptations in the maternal immune system. ${ }^{24}$

Sex hormone concentrations during pregnancy may also play an important role in the pathogenesis of pregnancy-associated gingivitis or periodontitis. ${ }^{25}$ The ratio of anaerobic to aerobic bacteria and the proportional levels of Bacteroides intermedia have been reported to be increased during pregnancy. ${ }^{26}$ The level of progesterone available in active form and the dysfunction of inflammatory cells may result in an increased chronic reaction, leading to a clinically exaggerated appearance of inflammation. ${ }^{27}$ Sex hormone fluctuation during pregnancy may involve changes in gingival tissue turnover. ${ }^{25}$ Even though the inflammation of periodontal tissues that occurs during pregnancy may be temporary and abates after childbirth, the destruction of periodontal tissue persists after childbirth. ${ }^{18}$

The functional dentition concept emphasized that a person needs a minimum number of natural teeth to have adequate dental function without the aid of prosthetic replacements. ${ }^{28,29}$ An earlier report suggested that people are able to chew most foods when they have more than 20 teeth; thus, 21 teeth became a cut-off value, since having 21 or more teeth is considered functional dentition. ${ }^{30}$

There are a few limitations that should be considered when reviewing the findings of this study. First, the design of the study was cross-sectional, and exposure and outcome are measured at the same time, which means that their inter-related sequences are unknown. ${ }^{31}$ Second, the data regarding reproductive history were collected by self-reporting, and was therefore subject to recall bias; there may have been disparities between the data details and the actual reproductive history. ${ }^{7}$ However, the KNHANES data are highly reliable because they were obtained from a nationwide, population-based and representative sample of Koreans, and the analysis used sample weights and adjustments for the complex sample design of the survey. ${ }^{32,33}$

\section{Conclusions}

This study investigated the relationship between the number of teeth in postmenopausal women and their age at their first/last deliveries and parity. It yielded several important findings, the most significant being the identification of an association between the number of natural teeth and a woman's age at her last delivery, as well as between the number of natural teeth and parity. Higher ages at last delivery and higher parity were found to be potential risk indicators for tooth loss in postmenopausal women.

\section{References}

1. Bragg JM, Kuzawa CW, Agustin SS, Banerjee MN, McDade TW. Age at menarche and parity are independently associated with AntiMullerian hormone, a marker of ovarian reserve, in Filipino young adult women. Am J Hum Biol. 2012;24:739-745.

2. Do KA, Treloar SA, Pandeya $\mathrm{N}$, et al. Predictive factors of age at menopause in a large Australian twin study. Hum Biol. 1998;70:1073-1091.

3. Gold EB. The timing of the age at which natural menopause occurs. Obstet Gynecol Clin North Am. 2011;38:425-440.

4. Luoto R, Kaprio J, Uutela A. Age at natural menopause and sociodemographic status in Finland. Am J Epidemiol. 1994;139:64-76.

5. Henderson KD, Bernstein L, Henderson B, Kolonel L, Pike MC. Predictors of the timing of natural menopause in the multiethnic cohort study. Am J Epidemiol. 2008;167:1287-1294.

6. Gold EB, Bromberger J, Crawford S, et al. Factors associated with age at natural menopause in a multiethnic sample of midlife women. Am J Epidemiol. 2001;153:865-874.

7. Ahn E, Lee J, Park YS, Noh HM, Kim BH. Association between delivery at an advanced maternal age and osteoporosis in elderly Korean women. JBMM. 2014.

8. Cho GJ, Shin JH, Yi KW, et al. Adolescent pregnancy is associated with osteoporosis in postmenopausal women. Menopause (New York, NY). 2012;19:456-460.

9. Sorensen MD, Hsi RS, Chi T, et al. Dietary intake of fiber, fruit and vegetables decreases the risk of incident kidney stones in women: A Women's Health Initiative report. J Urol. 2014;192:1694-1699.

10. Agarwal DP. Cardioprotective effects of light-moderate consumption of alcohol: A review of putative mechanisms. Alcohol and Alcoholism (Oxford, Oxfordshire). 2002;37:409-415. 
11. Oh JY, Yang YJ, Kim BS, Kang JH. Validity and reliability of Korean version of International Physical Activity Questionnaire (IPAQ) short form. J Korean Acad Fam Med. 2007;28:532-541.

12. Weisell RC. Body mass index as an indicator of obesity. Asia Pac $J$ Clin Nutr. 2002;11(Suppl 8):S681-684.

13. Oh SW, Shin SA, Yun YH, Yoo T, Huh BY. Cut-off point of BMI and obesity-related comorbidities and mortality in middle-aged Koreans. Obesity Research. 2004;12:2031-2040.

14. Wallace TM, Levy JC, Matthews DR. Use and abuse of HOMA modeling. Diabetes Care. 2004;27:1487-1495.

15. Chun YH, Kim HR, Han K, Park YG, Song HJ, Na KS. Total cholesterol and lipoprotein composition are associated with dry eye disease in Korean women. Lipids Health Dis. 2013;12:84.

16. Jeon JY, Ko SH, Kwon HS, et al. Prevalence of Diabetes and Prediabetes according to Fasting Plasma Glucose and HbA1c. Diabetes Metab J. 2013;37:349-357.

17. Weber MA, Julius S, Kjeldsen SE, et al. Blood pressure dependent and independent effects of antihypertensive treatment on clinical events in the VALUE Trial. Lancet. 2004;363:2049-2051.

18. Ueno M, Ohara S, Inoue M, TsuganeS, Kawaguchi Y. Association between parity and dentition status among Japanese women: Japan public health center-based oral health study. BMC Public Health. 2013;13:993.

19. Christensen K, Gaist D, Jeune B, Vaupel JW. A tooth per child? Lancet. 1998;352:204.

20. Russell SL, Ickovics JR, Yaffee RA. Parity \& untreated dental caries in US women. JDR. 2010;89:1091-1096.

21. Scheutz F, Baelum V, Matee MI, Mwangosi I. Motherhood and dental disease. Community Dental Health. 2002;19:67-72.

22. Walker AR, Dison E, Walker BF. Dental caries in South African rura black women who had large families and long lactations. J Trop Med Hyg. 1983;86:201-205
23. Laine MA. Effect of pregnancy on periodontal and dental health. Acta Odontol Scand. 2002;60:257-264.

24. Luppi P. How immune mechanisms are affected by pregnancy. Vaccine. 2003;21:3352-3357.

25. Barak $S$, Oettinger-Barak $O$, Oettinger $M$, Machtei EE, Peled $M$, Ohel G. Common oral manifestations during pregnancy: A review. Obstetrical \& Gynecological Survey. 2003;58:624-628.

26. Kornman KS, Loesche WJ. The subgingival microbial flora during pregnancy. J Periodontal Res. 1980;15:111-122.

27. Ojanotko-Harri AO, Harri MP, Hurttia HM, Sewon LA. Altered tissue metabolism of progesterone in pregnancy gingivitis and granuloma. J Clin Periodontol. 1991;18:262-266.

28. Ribeiro MT, Rosa MA, Lima RM, Vargas AM, Haddad JP, Ferreira EFE. Edentulism and shortened dental arch in Brazilian elderly from the National Survey of Oral Health 2003. Revista de Saude Publica. 2011:45:817-823.

29. Global goals for oral health in the year 2000. Federation Dentaire Internationale. International Dental Journal. 1982;32:74-77.

30. Ervin RB, Dye BA. Number of natural and prosthetic teeth impact nutrient intakes of older adults in the United States. Gerodontology. 2012;29:e693-702.

31. Choi HM, Han K, Park YG, Park JB. Associations Among Oral Hygiene Behavior and Hypertension Prevalence and Control: The 2008-2010 Korea National Health and Nutrition Examination Survey. J Periodontol. 2015:1-19.

32. Kim Y. The Korea National Health and Nutrition Examination Survey (KNHANES): Current status and challenges. Epidemiol Health. 2014;36:e2014002.

33. Lee WH, Wee JH, Kim DK, et al. Prevalence of subjective olfactory dysfunction and its risk factors: korean national health and nutrition examination survey. PloS One. 2013;8:e62725. 